\title{
Banded Convection Caused by Frontogenesis in a Conditionally, Symmetrically, and Inertially Unstable Environment
}

\author{
DAVID M. SCHULTZ* \\ Cooperative Institute for Mesoscale Meteorological Studies, University of Oklahoma, and NOAA/National Severe Storms Laboratory, \\ Norman, Oklahoma \\ JOHN A. KNOX \\ Faculty of Engineering, The University of Georgia, Athens, Georgia
}

(Manuscript received 5 July 2006, in final form 19 September 2006)

\begin{abstract}
Several east-west-oriented bands of clouds and light rain formed on 20 July 2005 over eastern Montana and the Dakotas. The cloud bands were spaced about $150 \mathrm{~km}$ apart, and the most intense band was about $20 \mathrm{~km}$ wide and $300 \mathrm{~km}$ long, featuring areas of maximum radar reflectivity factor of about $50 \mathrm{dBZ}$. The cloud bands formed poleward of an area of lower-tropospheric frontogenesis, where air of modest convective available potential energy was being lifted. During initiation and maintenance of the bands, mesoscale regions of dry symmetric and inertial instability were present in the region of the bands, suggesting a possible mechanism for the banding. Interpretation of the extant instabilities in the region of the bands was sensitive to the methodology to assess the instability. The release of these instabilities produced circulations with enough vertical motion to lift parcels to their lifting condensation level, resulting in the observed cloud bands. A high-resolution, numerical weather prediction model demonstrated that forecasting these types of events in such real-time models is possible, although the timing, evolution, and spacing of the bands were not faithfully reproduced. This case is compared to two previous cases in the literature where banded convection was associated with a combination of conditional, symmetric, and inertial instability.
\end{abstract}

\section{Introduction}

On 20 July 2005, several east-west-oriented cloud bands occurred in eastern Montana and the Dakotas (Fig. 1). Some light precipitation was observed with these bands (Fig. 2), although no severe weather was reported [National Climatic Data Center (NCDC 2005)]. The nearly regular spacing of these bands in a region isolated from other convective storms was curious.

The purpose of this article is to explore the formation and maintenance of these bands. Section 2 provides an

\footnotetext{
* Current affiliation: Division of Atmospheric Sciences, Department of Physical Sciences, University of Helsinki, and Finnish Meteorological Institute, Helsinki, Finland.

Corresponding author address: Dr. David M. Schultz, NOAA/ NSSL/FRDD, Suite 4356, 120 David L. Boren Blvd., Norman, OK 73072-7326.

E-mail: david.schultz@noaa.gov
}

DOI: $10.1175 / M W R 3400.1$

(C) 2007 American Meteorological Society overview of the synoptic and mesoscale environment in which these bands formed. Section 3 discusses how the ingredients came together to produce an environment favorable for deep, moist convection. The possible mechanisms for banding are considered in section 4 . Section 5 presents a real-time mesoscale model forecast, indicating that such models have the capability to produce these bands. Section 6 relates this case to previously published theoretical concepts related to symmetric and inertial instability, whereas section 7 discusses the similarity of this case to two previously published observed cases. Finally, section 8 concludes this paper.

\section{Synoptic and mesoscale overview}

Analyses from the Rapid Update Cycle (RUC; Benjamin et al. 2004) are used to illustrate the synoptic and mesoscale characteristics of the environment in which the bands developed. At the time of this event, the RUC was run operationally with a horizontal grid spac- 


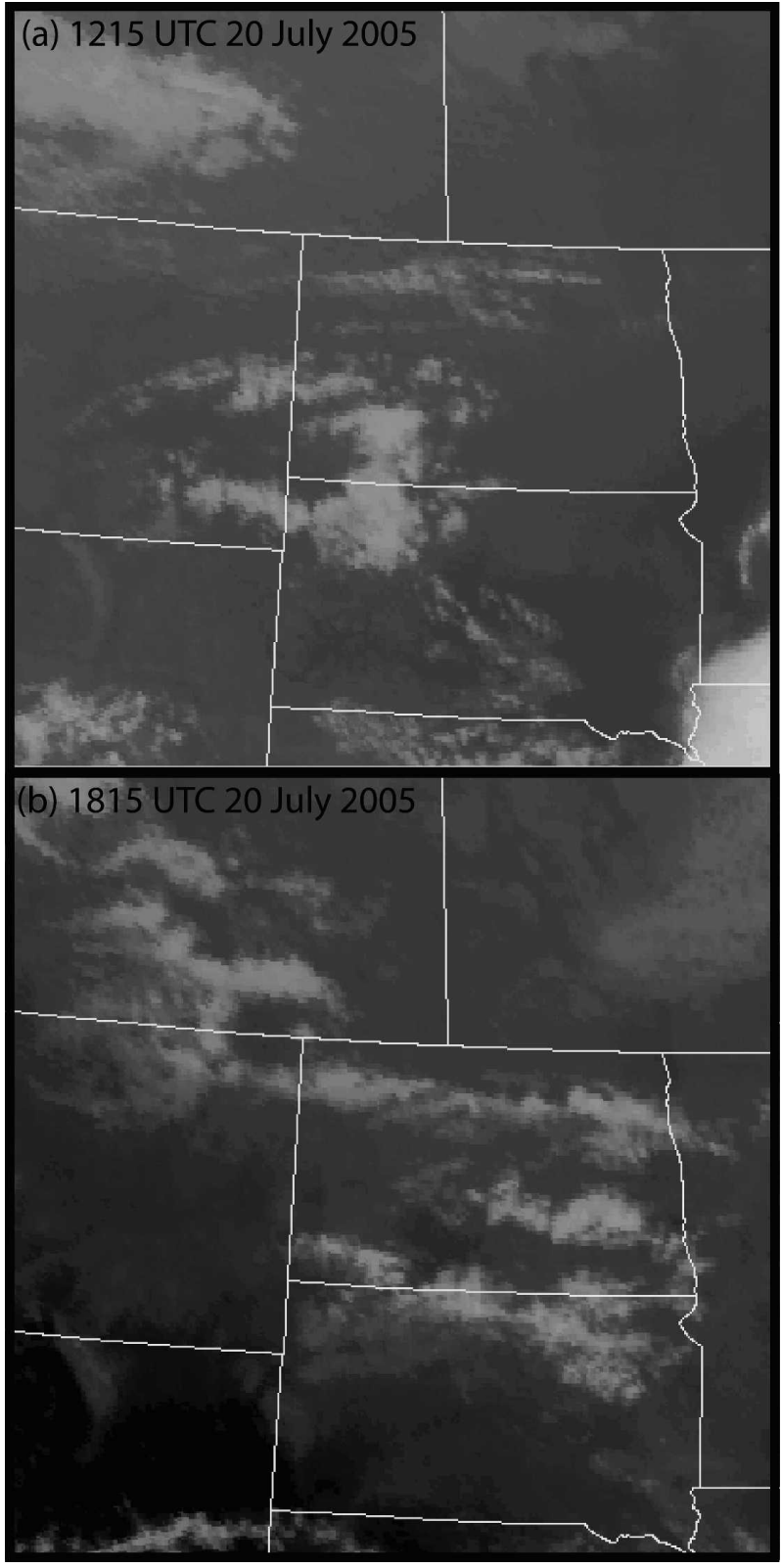

FIG. 1. Geostationary Operational Environmental Satellite-12 4-km longwave infrared (channel 4) satellite imagery at (a) 1215 and (b) 1815 UTC 20 Jul 2005.

ing of $13 \mathrm{~km}$ and 50 levels. The RUC output used to create the figures in this paper was received at the Storm Prediction Center at a reduced grid spacing of 40 $\mathrm{km}$. Thus, the data used here can only resolve the environment of the bands, not the bands themselves. A note of caution is warranted on calculating highly derived fields like absolute vorticity and potential vorticity (PV) using RUC output. Given the sensitivity of these calculations to small variations in wind speed (e.g., Doswell 1977) and stability, the exact shape and

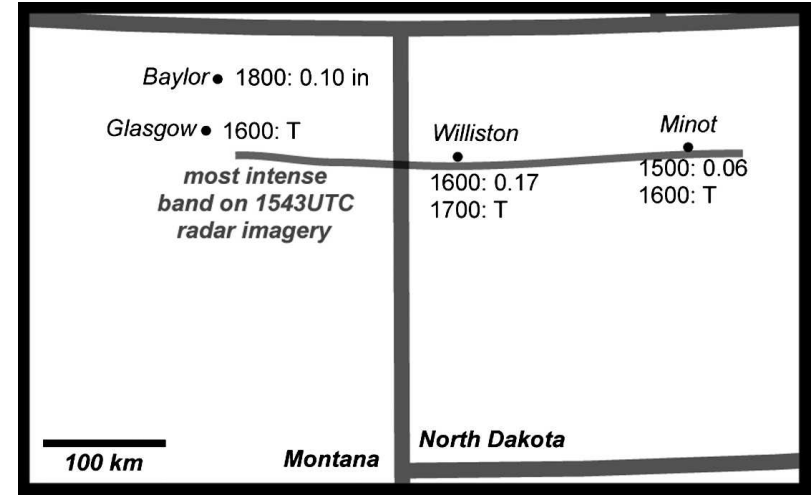

FIG. 2. Observed precipitation (in., $\mathrm{T}=$ trace) on $20 \mathrm{Jul} 2005$ in MT and ND from the banded convection. Times represent UTC ending time of precipitation from NCDC's hourly precipitation database. The thin gray line represents the approximate location of the most intense band, which appears as a broken line on the 1543 UTC radar imagery (Fig. 5b)

magnitude of these fields should be questioned. Smallscale details of what the atmosphere looks like may not be faithfully reproduced. But, if an area of negative absolute vorticity several hundred kilometers in horizontal scale is present, we can possess more confidence that at least some aspects are reproduced in the model analysis.

At 0000 UTC 20 July, the 500-hPa flow was characterized by a closed anticyclone over the Four Corners area and a zonally oriented jet streak along the western U.S.-Canada border associated with a trailing region of vorticity from a trough in central Canada (Fig. 3a). At 1200 UTC, the trough had moved eastward to western Ontario (Fig. 3b).

At the surface, a weak low pressure center moved from south-central Montana at 0000 UTC (Fig. 4a) to northeast Wyoming at 0900 UTC (Fig. 4b) and southward after that time as a surface high pressure center moved in from Alberta, Canada, and increased in strength (Figs. 4c,d). This combination of a surface low to the south and high to the north, coupled with a broad east-west-oriented lower-tropospheric baroclinic zone, produced a confluent region of flow favorable for frontogenesis, especially at 0900 UTC (Fig. 4b).

Around 0800 UTC, east-west-oriented bands of clouds began forming in eastern Montana. These bands moved primarily eastward with little north-south movement, but with some redevelopment of the bands to the west. The most prominent set of four bands were most apparent on longwave infrared (channel 4) satellite imagery (Fig. 1a), although a few appeared on radar imagery around 1200 UTC (Figs. 5 and 6a). By 1815 UTC, three well-defined bands were apparent in infrared satellite imagery with about $150-\mathrm{km}$ spacing (Fig. 


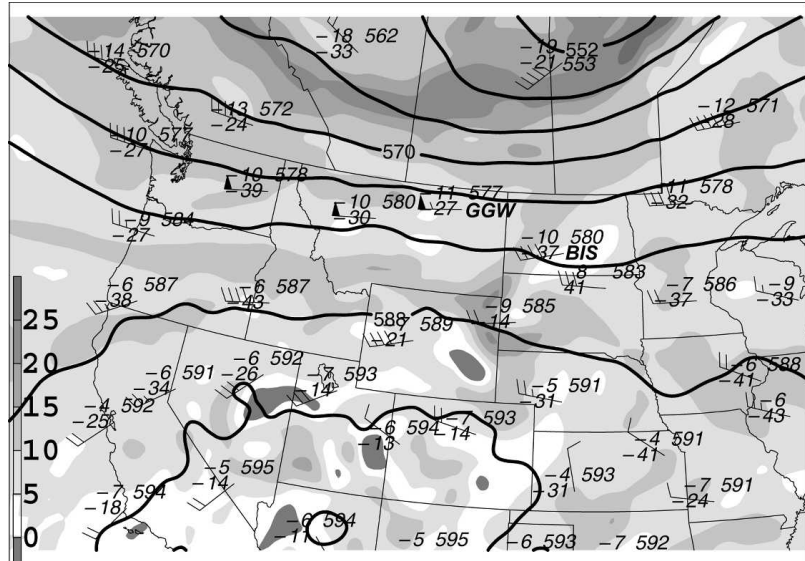

(a) 0000 UTC 20 July 2005: RUC 500-hPa ABSOLUTE VORTICITY \& HEIGHT

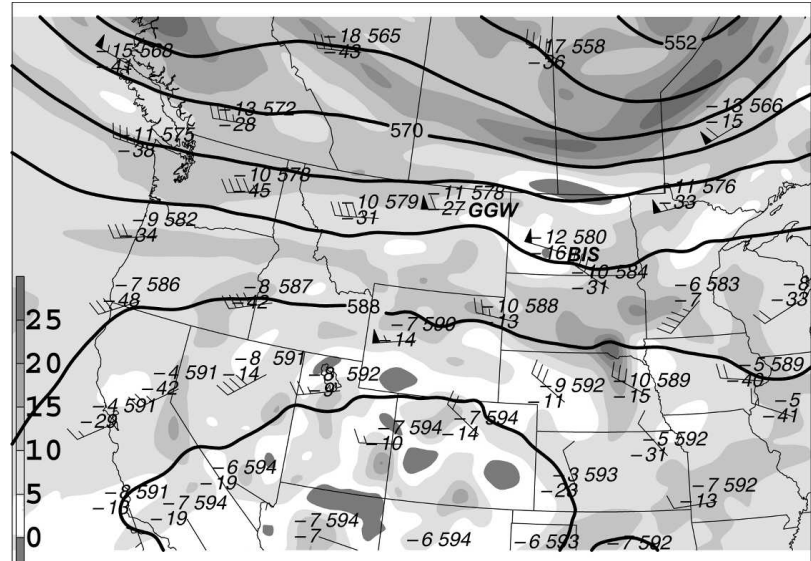

(b) 1200 UTC 20 July 2005: RUC 500-hPa ABSOLUTE VORTICITY \& HEIGHT

FIG. 3. 500-hPa maps from the RUC initializations at (a) 0000 and (b) 1200 UTC 20 Jul 2005. Geopotential height (black lines every $6 \mathrm{dam})$ and absolute vorticity $\left(10^{-5} \mathrm{~s}^{-1}\right.$, shaded according to scale). Station models for observed upper-air data is standard: geopotential height (dam), temperature and dewpoint $\left({ }^{\circ} \mathrm{C}\right.$ ), and horizontal wind (pennant, full barb, and half-barb denote 25,5 , and $2.5 \mathrm{~m} \mathrm{~s}^{-1}$, respectively). Locations of soundings from Glasgow, MT, and Bismarck, ND, in Fig. 7 are labeled as GGW and BIS, respectively.

1b). A broken line of radar reflectivity factor indicated the position of the northernmost and most intense band, which was roughly $15-20 \mathrm{~km}$ wide and $300 \mathrm{~km}$ long (Figs. 5b and 6a). Regions of maximum radar reflectivity factor were about $50 \mathrm{dBZ}$, producing the precipitation in Fig. 2 (Figs. 5b and 6). The radar reflectivity factor reached nearly $10 \mathrm{~km}$ in depth (Fig. 6b), indicating a deep updraft. Around 0000 UTC 21 July, the cloud bands had dissipated (not shown).

\section{Ingredients for deep, moist convection}

These bands formed in an environment otherwise typical of convection in the summer in the northern United States. Low-level moisture was limited, as nearsurface dewpoints were only $10^{\circ}-15^{\circ} \mathrm{C}$ (Fig. 7). A combination of a 1-km-deep surface mixed layer and a nearisentropic layer at 800-550 hPa (Fig. 7) implied high cloud bases, if clouds formed. The most unstable convective available potential energy (MUCAPE) at Glasgow, Montana, at 0000 UTC was only $90 \mathrm{~J} \mathrm{~kg}^{-1}$, but was higher at Bismarck, North Dakota, with $1039 \mathrm{~J} \mathrm{~kg}^{-1}$ (Figs. 7a,b). By 1200 UTC, the MUCAPE was nearly nonexistent $\left(3 \mathrm{~J} \mathrm{~kg}^{-1}\right)$ at Glasgow, but also reduced $\left(353 \mathrm{~J} \mathrm{~kg}^{-1}\right.$ ) at Bismarck (Figs. 7a,b). Analyses from the RUC were comparable to the MUCAPE values from the observed soundings (Figs. 8a,c). This environment favored convective storms with high cloud bases. The potential for subcloud evaporation in such a dry environment was great, possibly indicating why precipitation from such intense reflectivity was relatively light (cf. Figs. 2 and 6).
Analyses from the RUC show the formation of the MUCAPE and its spatial variability (Fig. 8). At 0000 UTC 20 July, a large region of high MUCAPE (>2000 $\mathrm{J} \mathrm{kg}^{-1}$ ) occurred in the Dakotas, while a region of low dry absolute stability (as measured by the difference in potential temperature between 500 and $700 \mathrm{hPa}$ ) was found in Wyoming and south-central Montana (Fig. 8 a). Surface dewpoints in the region where the bands would later form were relatively low $\left(0^{\circ}-8^{\circ} \mathrm{C}\right)$, and MUCAPE was nonexistent (Fig. 8a). With the arrival of the surface cyclone into northeast Wyoming by 0900 UTC (Fig. 4b), strengthening surface geostrophic easterlies advected moisture westward into the region of band initiation at the same time as the low-stability midtropospheric air arrived from the west (Fig. 8b). This superposition of low-level moisture and midtropospheric low-stability air created modest MUCAPE (100-1000 $\mathrm{J} \mathrm{kg}^{-1}$ ) in the region where the bands initiated (Fig. 8b). According to the RUC analyses, modest MUCAPE persisted just south of region where the bands formed throughout their lifetime (Figs. 8c,d). This unstable air likely served as the inflow to the bands after having risen aloft above the frontal zone.

Thus, this event had the three ingredients for deep, moist convection: lift, moisture, and instability (e.g., McNulty 1978; Johns and Doswell 1992). Lift was provided by lower-tropospheric frontogenesis in a synoptic situation rather unimpressive for quasigeostrophic ascent (e.g., straight zonal flow). Modest MUCAPE was produced in the region where the bands developed by the superposition of low-level moisture brought westward by a strengthening easterly flow and eastward- 

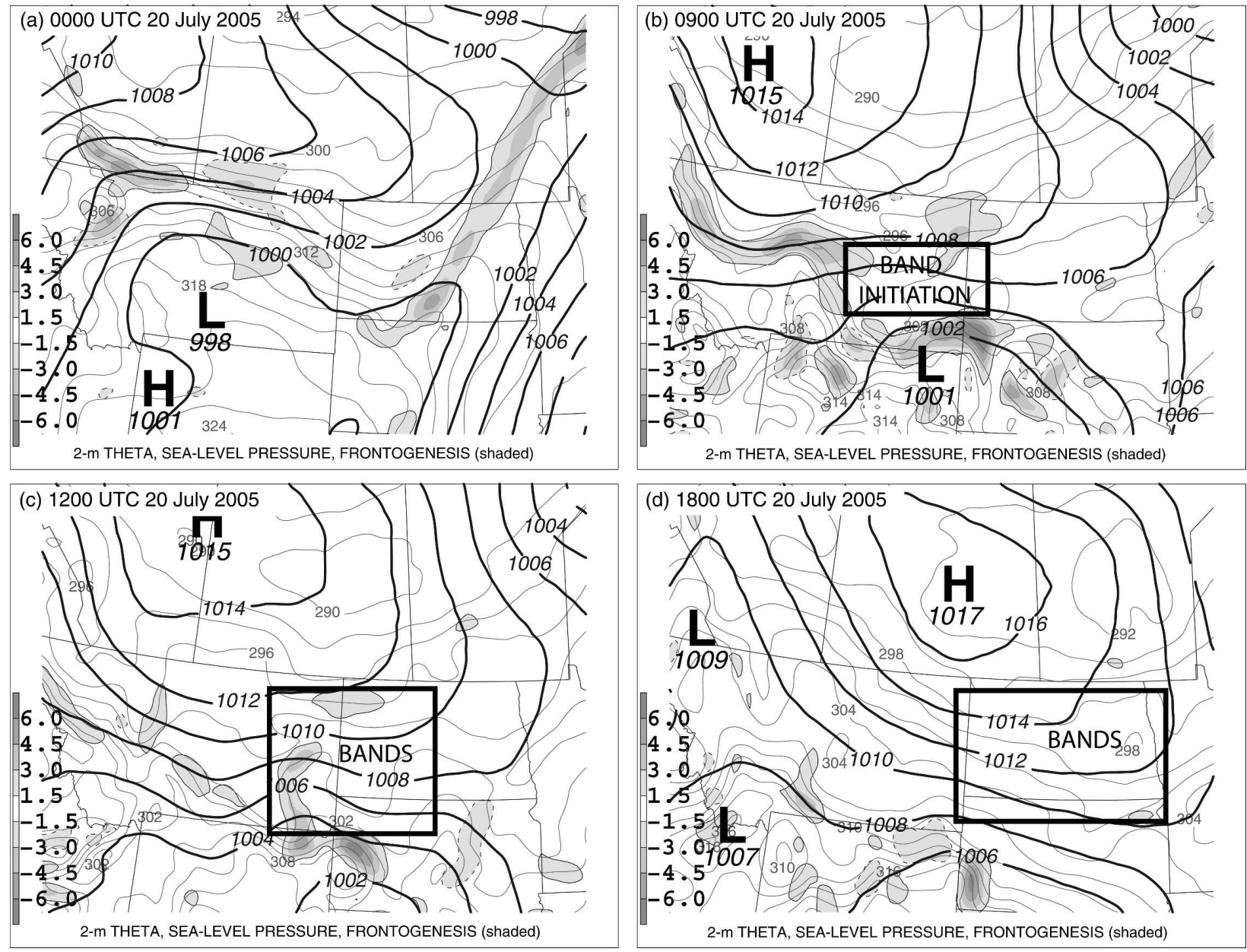

FIG. 4. Surface maps from the RUC initializations at (a) 0000, (b) 0900, (c) 1200, and (d) 1800 UTC 20 Jul 2005. Potential temperature at $2 \mathrm{~m}$ (gray lines every $2 \mathrm{~K}$ ), sea level pressure (black lines every $2 \mathrm{hPa}$ ), and 900 -hPa frontogenesis $\left[\mathrm{K}(100 \mathrm{~km})^{-1}(3 \mathrm{~h})^{-1}\right.$, shaded according to scale, solid (dashed) lines surrounding shading represent frontogenesis (frontolysis) values of $\left.\pm 1.5 \mathrm{~K}(100 \mathrm{~km})^{-1}(3 \mathrm{~h})^{-1}\right]$. Rectangles identify regions where banded clouds and precipitation were observed from satellite and radar imagery.

moving midtropospheric low-stability air. This unstable air was lifted aloft over the frontal zone into the region where the bands formed. Given the dryness of the environment, however, substantial lifting (to above 600$700 \mathrm{hPa}$ ) was required to reach the level of free convection.

\section{Mechanisms for banding}

With the conditions present for deep, moist convection, what caused the convection to organize in bands over a mesoscale region? One possible mechanism is symmetric instability (reviewed by Schultz and Schumacher 1999). The condition for dry symmetric instability is that the atmosphere is inertially and gravitationally (absolutely) stable and that PV is negative. The condition for moist symmetric instability is that the atmosphere is inertially and conditionally stable and that moist PV is negative. Another possible candidate mechanism for organizing the convection is inertial instability (reviewed by Knox 2003). The condition for inertial instability is that the product of the planetary vorticity and the absolute vorticity is negative. Thus, for the Northern Hemisphere, the condition for inertial instability is negative absolute vorticity.

To test the hypothesis that these instabilities may have been present in the region where the bands formed, we next examine horizontal maps and vertical cross sections of inertial, symmetric, and conditional stability. The form of the absolute vorticity, PV, and moist PV to evaluate inertial, dry symmetric instability, and moist symmetric instability, respectively, is a topic that has generated considerable discussion. For example, Schultz and Schumacher (1999) advocate using the "geostrophic" wind. [The quotes around the word geostrophic (hereafter dropped) are meant to imply 


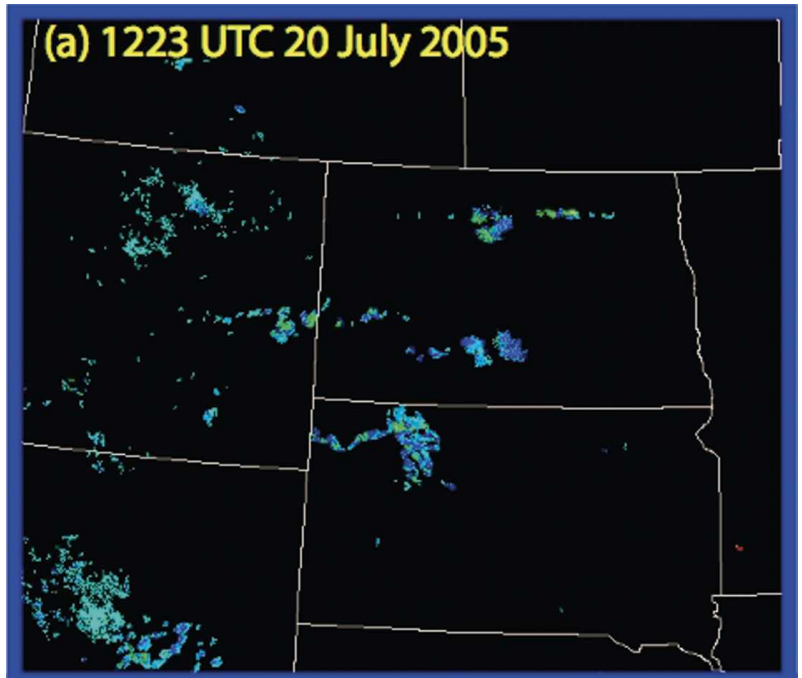

(b) 1543 UTC 20 July 2005

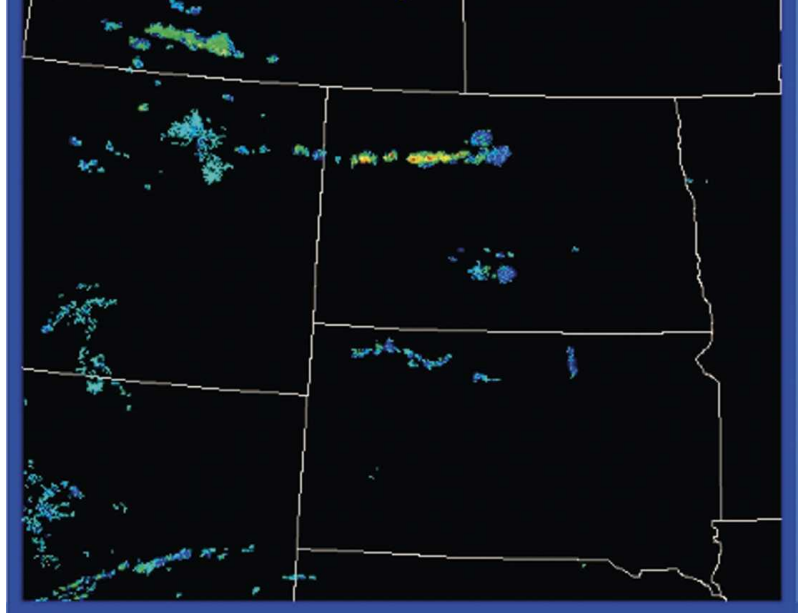

(c) 1815 UTC 20 July 2005

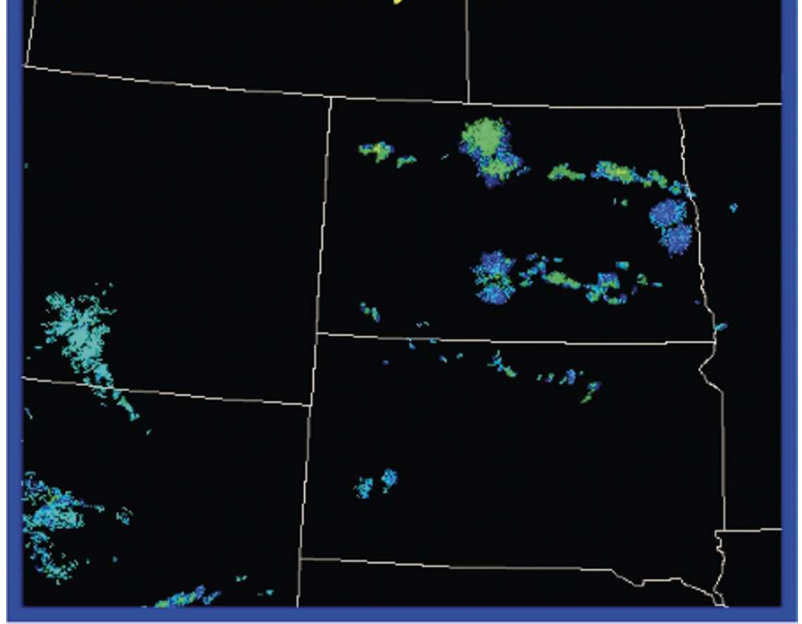

FIG. 5. Unfiltered, $0.5^{\circ}$ elevation-angle, radar reflectivity factor (dBZ) from the nationwide Weather Surveillance Radar-1988 Doppler network at (a) 1223, (b) 1543, and (c) 1815 UTC $20 \mathrm{Jul}$ 2005. that the geostrophic wind is calculated from the geopotential height or total pressure field without filtering geostrophically unbalanced perturbations away (e.g., Schultz and Schumacher 1999, p. 2713).] In contrast, others prefer using the total wind (e.g., Gray and Thorpe 2001; Clark et al. 2002; Jurewicz and Evans 2004; Novak et al. 2004, 2006). In this paper, we calculate the instability parameters using the both the geostrophic wind and the total wind. In general, calculations performed using the geostrophic wind indicated more instability, as found in previous studies (e.g., Clark et al. 2002; Jurewicz and Evans 2004; Novak et al. 2006). Whether the geostrophic or total wind is more appropriate in calculating symmetric and inertial instability parameters remains an open question (e.g., Gray and Thorpe 2001; Novak et al. 2006, 19-21; NielsenGammon and Gold 2007).

At 0000 UTC 20 July, a large region of negative PV (calculated using the total wind) was observed throughout Montana and Wyoming (Fig. 9a). This region moved to eastern Montana and the western Dakotas by 0900 UTC, in the location and east of where the bands originated (Fig. 9b). Later, this region moved into the central and eastern Dakotas (Figs. 9c,d). Small regions of negative absolute vorticity were present within and adjacent to the negative PV (Figs. 9a-c), although they dissipated later in the day (Fig. 9d). The area of this region of negative PV was similar to the spatial scale of the region where the bands occurred.

In contrast, calculations involving the geostrophic wind revealed much more inertial instability, even despite the relatively straight flow in the midtroposphere during this period over the region (Fig. 10). At 0000 UTC 20 July, scattered regions of negative absolute geostrophic vorticity and negative geostrophic PV $\left(\mathrm{PV}_{g}\right)$ were observed throughout Montana and Wyoming (Fig. 10a). The biggest area in southwestern Montana, associated with a small-scale $600-\mathrm{hPa}$ ridge, moved to eastern Montana by 0900 UTC, in the location where the bands originated (Fig. 10b). This region consisted of negative $\mathrm{PV}_{g}$ encompassing a smaller region of negative geostrophic absolute vorticity. Later in the day, the negative geostrophic absolute vorticity largely dissipated while the negative $\mathrm{PV}_{g}$ remained (Figs. 10c,d).

A north-south cross section from the RUC through the region where the bands formed showed the vertical extent of the unstable regions (Figs. 11a,b). A region of negative PV is present, although parts of this region seem to be related to small regions of negative absolute vorticity (Fig. 11a). The ascent above the region of frontogenesis showed the lifting of the moist conditionally unstable air (Fig. 11b), as discussed in section 3. 


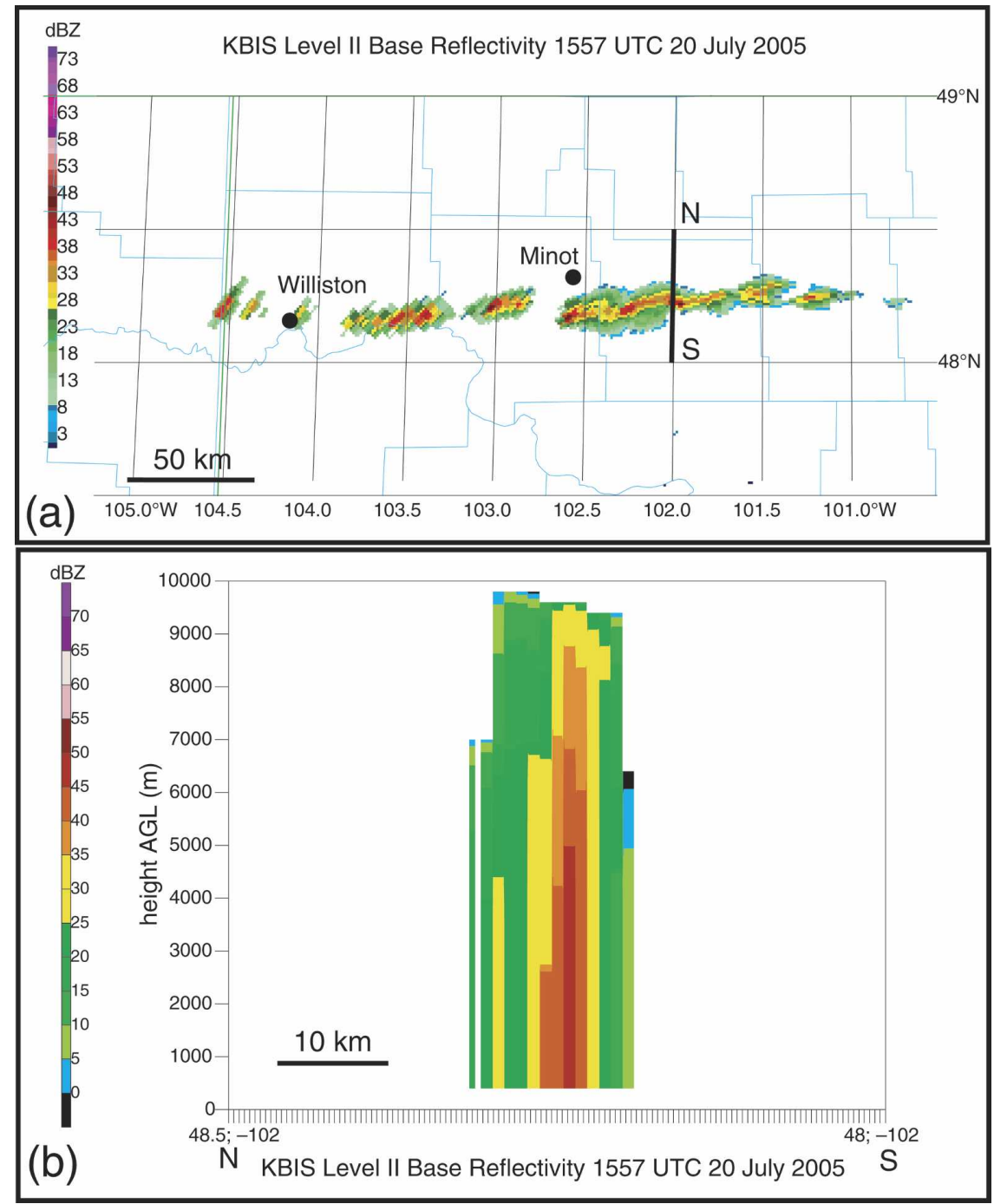

FIG. 6. Radar reflectivity factor (dBZ) from Bismarck, ND, radar (KBIS) at 1557 UTC 20 Jul 2005: (a) horizontal map with location of cross section N-S identified and (b) vertical cross section along N-S. Reflectivity scales in (a) and (b) are similar, but not exactly identical. The radar feedhorn elevation is $535.1 \mathrm{~m}$ above mean sea level. Data are vertically interpolated between scans in (b). KBIS is $270 \mathrm{~km}$ southeast of Williston and $170 \mathrm{~km}$ south-southeast of Minot.

Maxima of vertical motion occurred above the surface position of the front and within the region of negative absolute vorticity and PV aloft (Fig. 11b). Horizontal maps of the unstable regions show that the symmetrically unstable air was located above the front in the region where the bands formed (Fig. 11c). This is also the same region where conditionally unstable air was located in the lower troposphere above and south of the region of low-level frontogenesis (Fig. 11d). Thus, the region where the bands formed was conditionally, symmetrically, and occasionally inertially, unstable.

The computations of stability using the geostrophic wind tell a different tale (Fig. 12). A region of negative absolute geostrophic vorticity spanned the troposphere (Fig. 12). In the lower troposphere, a region of negative $\mathrm{PV}_{g}$ lay adjacent to the region of negative geostrophic absolute vorticity. Although a small layer of dry absolutely or neutrally stable air was present in the cross section, the majority of the region of negative $\mathrm{PV}_{g}$ was absolutely stable (Fig. 12), but conditionally unstable (Fig. 11b). A horizontal map of the unstable regions shows that the symmetrically and inertially unstable air was located above the front in the region where the bands formed (Fig. 10b). 


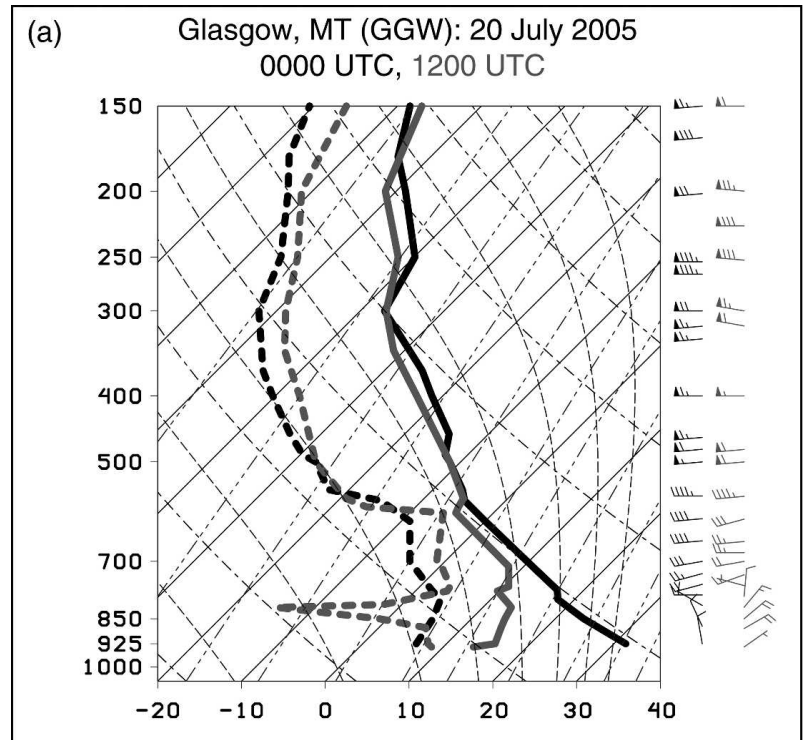

(b) $\quad$ Bismarck, ND (BIS): 20 July 2005 0000 UTC, 1200 UTC

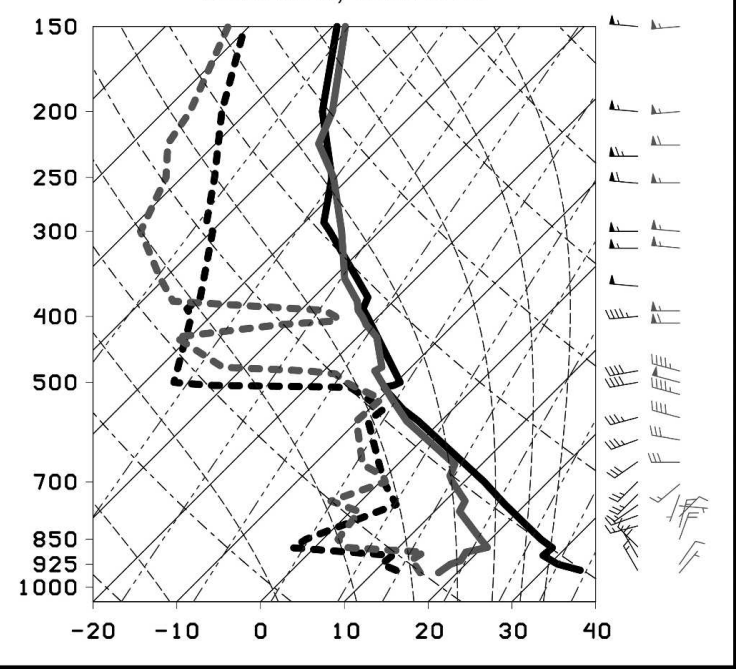

FIG. 7. Skew $T-\log p$ charts on 20 Jul 2005 at (a) Glasgow, MT, and (b) Bismarck, ND. Temperature (solid lines), dewpoint (dashed lines), and horizontal wind (pennant, full barb, and halfbarb denote 25,5 , and $2.5 \mathrm{~m} \mathrm{~s}^{-1}$, respectively). Black lines represent 0000 UTC profiles, and gray lines represent 1200 UTC profiles.

Given the lack of large-scale saturation, as seen in the satellite imagery (Fig. 1) and the lack of moisture in the soundings (Fig. 7), moist symmetric instability seems unlikely to explain the presence of the bands. It would appear that the circulations that spawned the cloud bands formed first in an unsaturated environment, then saturated later. This process is different than banding in extratropical cyclones (e.g., Novak et al. 2004, 2006) where large-scale saturation poleward of the warm front is typically established before bands form. Thus, we eliminate moist symmetric instability from consideration as a possible mechanism.

Gravity waves are another candidate mechanism for banding (e.g., Uccellini and Koch 1987). We can eliminate that mechanism because the bands did not appear to be propagating relative to the flow. Furthermore, the vertical wind shear in the layer where clouds would form (roughly 600-400 hPa) was westerly (Fig. 7), indicating that any banded structures would be aligned east-west. The thermal wind between 600 and $400 \mathrm{hPa}$ also had the same approximate east-west orientation (not shown), in agreement with symmetric instability where the expected band orientation is close to the thermal wind. Circulations produced by the release of inertial instability are also aligned along the wind. Thus, given the presence of large regions of dry symmetric instability with embedded regions of inertial instability, the most likely candidate to explain the banding is the release of dry symmetric and/or inertial instability in the presence of conditionally unstable air lifted by frontogenesis.

\section{Can real-time, high-resolution, mesoscale models predict these bands?}

A real-time Weather Research and Forecasting model (WRF; Skamarock et al. 2005) forecast performed by the National Center for Atmospheric Research Mesoscale and Microscale Meteorology Division also produced banded convection for this event (Fig. 13). The model was the 4-km horizontal grid-spacing version of the Advanced Research WRF run during the Spring/Summer High-Resolution Forecast Experiment (more information available online at http://box.mmm. ucar.edu/projects/wrf_spring/). Boundary and initial conditions for the WRF run were provided by the National Oceanic and Atmospheric Administration (NOAA) National Centers for Environmental Prediction (NCEP) North American Model, and the WRF run was initialized at 0000 UTC 20 July 2005.

Although no precipitation fell at the surface in the model (not shown), the simulated composite radar reflectivity factor showed bands forming in south-central Montana at 0400 UTC (Fig. 13a), moving across the Dakotas by 1200 UTC (Fig. 13b), and moving into Minnesota after 1800 UTC (Figs. 13c,d). These forecasted bands formed about $5 \mathrm{~h}$ earlier than observed and occurred farther south and east of their observed locations (cf. Figs. 5 and 13), indicating that the model possessed some sensitivity to the details of the bands. The bands also seemed to be better defined in the model for a longer time than occurred in the atmosphere.

A closer look at the region around the most intense 

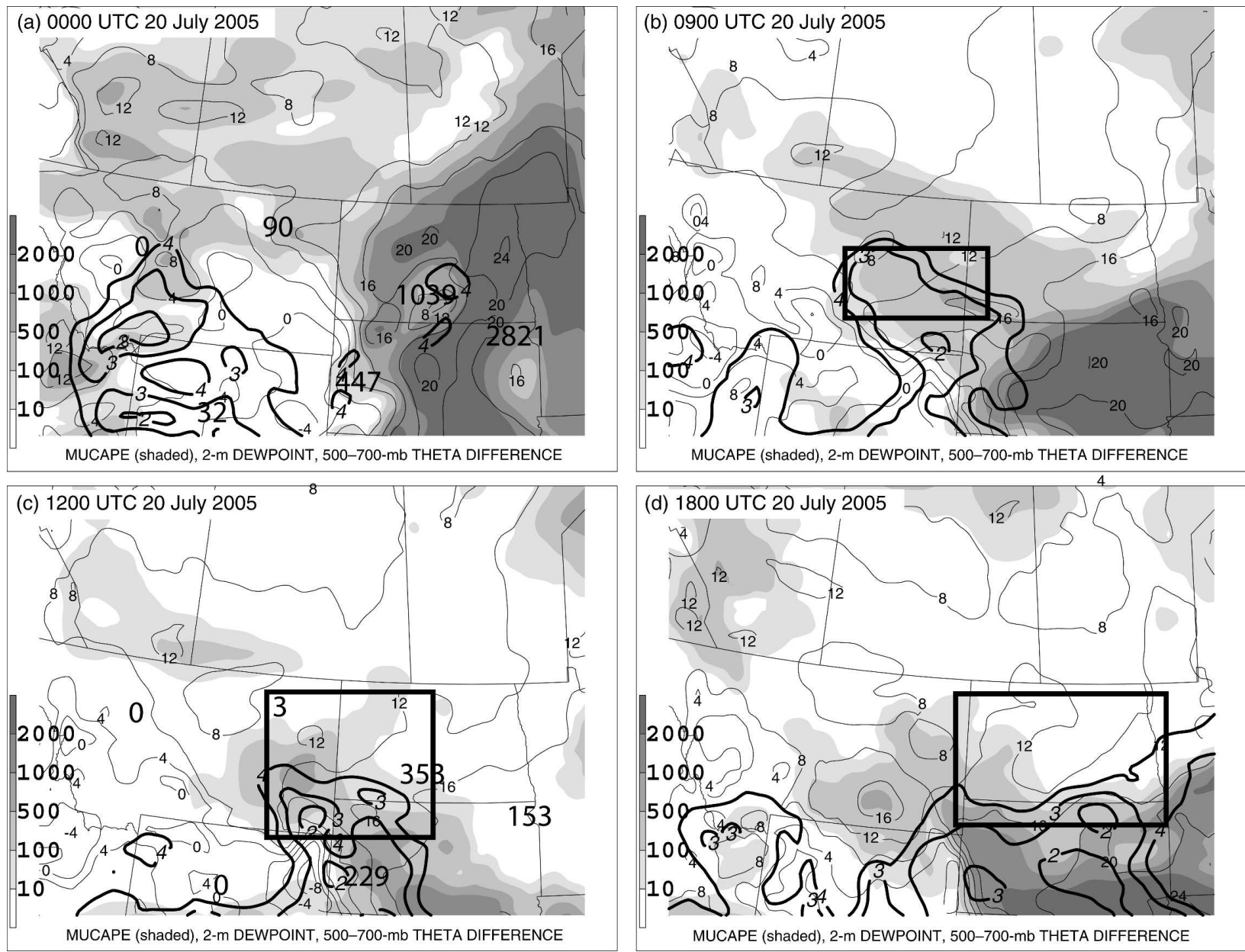

FIG. 8. RUC initializations at (a) 0000, (b) 0900, (c) 1200, and (d) 1800 UTC $20 \mathrm{Jul} 2005$. MUCAPE (J kg-1, shaded according to scale), 2-m dewpoint temperature (gray lines every $4 \mathrm{~K}$ ), and the difference in potential temperature between 500 and $700 \mathrm{hPa}$ (black lines every $1 \mathrm{~K}$ for values less than $4 \mathrm{~K}$ ). MUCAPE from the RUC is calculated by first averaging the potential temperature and water vapor mixing ratio in the lowest seven levels of the RUC (about $45-55 \mathrm{hPa}$ ), then by finding the most buoyant parcel within $300 \mathrm{hPa}$ of the surface. Large numbers in (a) and (c) represent observed MUCAPE from radiosonde data, calculated by finding the most unstable parcel (unmixed) within $300 \mathrm{hPa}$ of the surface and using the virtual temperature correction (Doswell and Rasmussen 1994). Rectangles identify regions where banded clouds and precipitation were observed from satellite and radar imagery.

band in the simulated radar reflectivity factor at 1200 UTC (Fig. 13b) reveals the following (Fig. 14). The most intense band was just one of a number of columns of negative PV and negative absolute vorticity in the model forecast in the region where the bands occurred (Fig. 14a), indicating the potential for the release of dry symmetric and inertial instability, respectively. The most intense band appears to be associated with a particularly intense and deep region of instability, suggesting that the ascent associated with the band may have been generating inertial instability, as in the so-called $\Delta M$-adjustment mechanism (e.g., Holt and Thorpe 1991). The region where bands occurred neutralized a portion of a larger horizontal region of negative $\mathrm{PV}$ in the layer 600-650 hPa (Fig. 14b).
Animations of these fields (not shown) show that the region of negative PV existed at the initial time and was advected eastward with the mean flow. The area of negative PV in the WRF was comparable to the area of the observed bands in satellite imagery (Fig. 1) and the region of negative PV in the RUC (Figs. 9 and 10). Circulations developed at 0200 UTC within this region, neutralizing the negative PV in the model. The bands remained stationary relative to the flow and to the negative PV region as a whole, further evidence that they are associated with the release of dry symmetric and/or inertial instability. By 1900 UTC, nearly the whole region of negative PV was consumed by the circulations, which continued for several more hours.

The scale of the bands is not consistent between the 


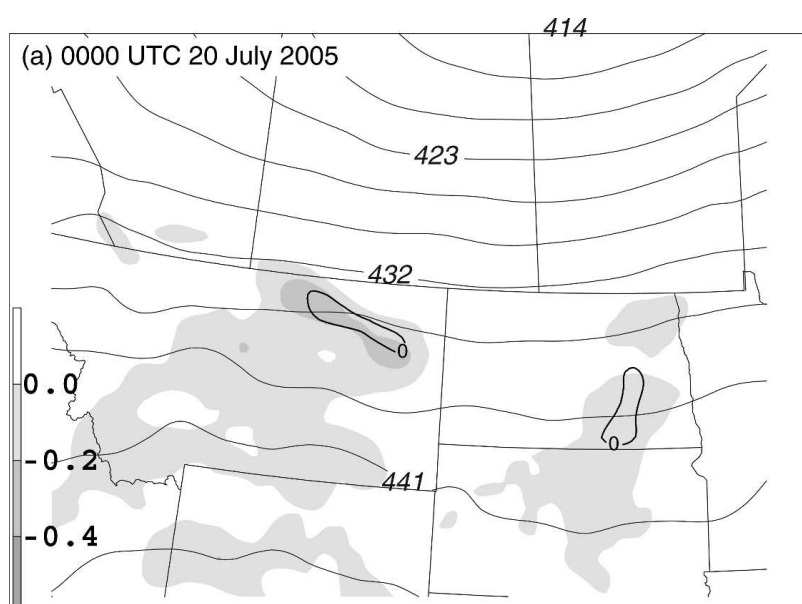

(a) 600-650-mb NEGATIVE PV, 600-mb ABSOLUTE VORTICITY and HEIGHT

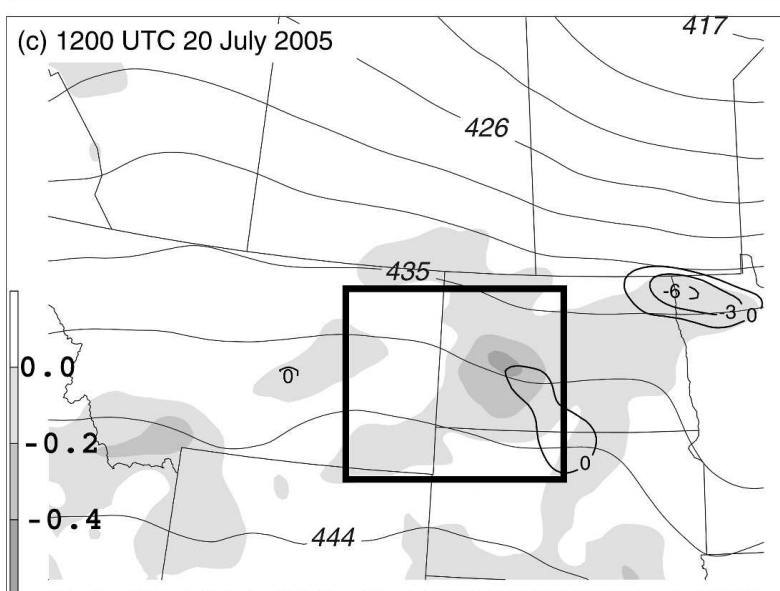

(c) 600-650-mb NEGATIVE PV, 600-mb ABSOLUTE VORTICITY and HEIGHT

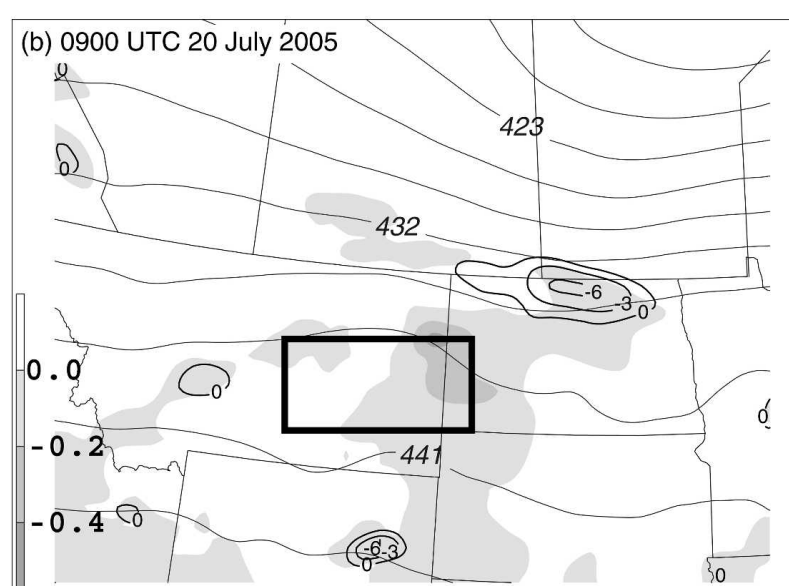

(b) 600-650-mb NEGATIVE PV, 600-mb ABSOLUTE VORTICITY and HEIGHT

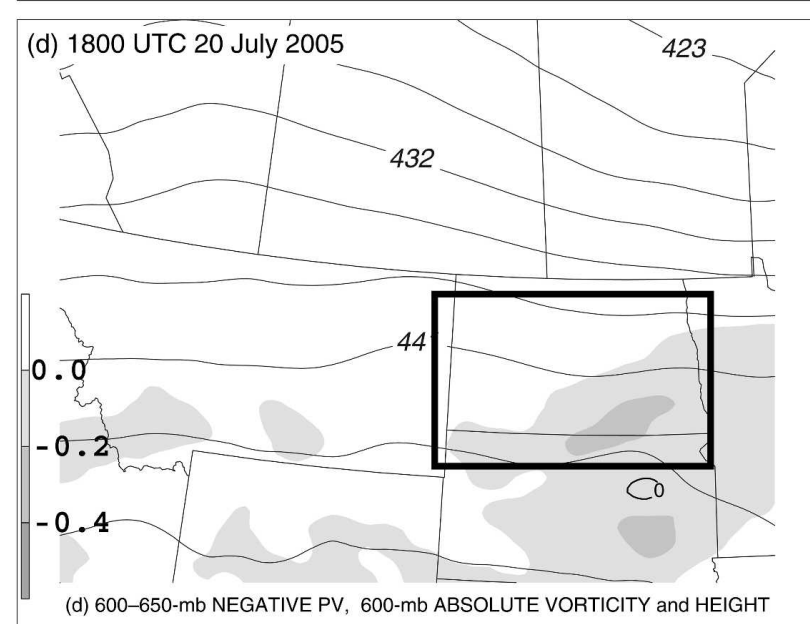

FIG. 9. RUC initializations at (a) 0000, (b) 0900, (c) 1200, and (d) 1800 UTC 20 Jul 2005. Negative PV over the layer 600-650 hPa $\left(10^{-6} \mathrm{~K} \mathrm{~m}^{2} \mathrm{~kg}^{-1} \mathrm{~s}^{-1}\right.$, shaded according to scale), negative $600-\mathrm{hPa}$ absolute vorticity (black lines every $-3 \times 10^{-5} \mathrm{~s}^{-1}$ starting at 0 ), and $600-\mathrm{hPa}$ geopotential height (gray lines every $3 \mathrm{dam}$ ). Rectangles identify regions where banded clouds and precipitation were observed from satellite and radar imagery.

observations (about $150 \mathrm{~km}$ ) and the model (about 50 $\mathrm{km})$. We proffer two possible explanations. First, satellite observations show occasional weaker bands with a smaller spacing than $150 \mathrm{~km}$ (Fig. 1), suggesting that these weaker bands never fully develop. One argument might be that subsidence associated with the convection from the stronger bands inhibited the weaker bands, favoring a $150-\mathrm{km}$ wavelength for the strongest bands. Second, inertial instability in the middle atmosphere in numerical models tends to maximize at the smallest resolvable scales, although larger-scale forcings (e.g., Rossby waves) in the real atmosphere organize the instability into larger sizes that are then observable by satellite (Hitchman et al. 1987). Possibly, such an effect occurred in these bands in the midtroposphere.

Real-time forecast models have the potential to capture these bands, although timing and location errors may occur, as is to be expected with such highresolution model forecasts (e.g., Roebber et al. 2004). Although the highly detailed fields and frequent output allow potential hypotheses to be tested regarding the origin and maintenance mechanisms of the bands, the WRF hourly output available to us was inadequate to explore the evolution of individual circulation cells. Thus, the questions we can address with this data are necessarily limited.

Based on the results from the observed data, the RUC analyses, and the WRF forecasts, we offer the following hypothesis for the origin and maintenance of the bands. A region of unsaturated negative PV moves over a frontal zone. Horizontal circulations about 50 $\mathrm{km}$ apart develop in the negative PV due primarily to the release of dry symmetric instability, although the release of inertial instability may also be important. 

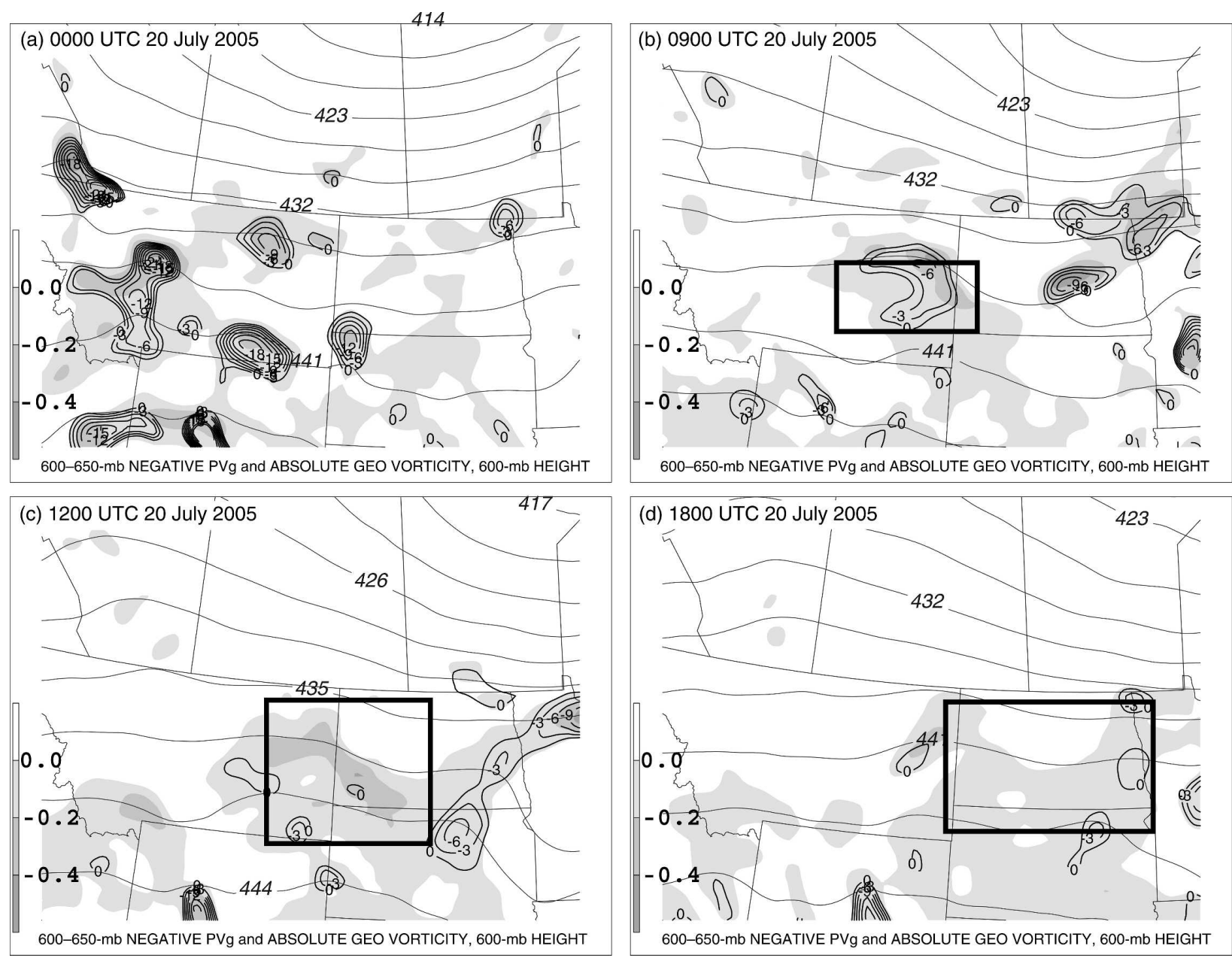

FIG. 10. Same as in Fig. 9, but for negative $\mathrm{PV}_{g}$ (shaded) and negative absolute geostrophic vorticity (black lines).

Some of these circulations produce enough vertical motion to lift parcels to their lifting condensation level, resulting in deep, moist convection.

\section{Similarities to previous theory}

Given the complexity of this situation with conditional, symmetric, and inertial instabilities occurring in the presence of finite-amplitude forcing for ascent (i.e., frontogenesis), how banded structures would develop is unclear. Published theoretical research on fluid instabilities is not sufficiently advanced to address such a complex situation. Thus, this section attempts to link the observed structures with much simpler existing theoretical studies.

The structure of unstable disturbances in a region of dry symmetric instability was studied by Jones and Thorpe (1992). Whereas previous studies showed that two-dimensional domains both with uniform negative PV and with finite regions of negative PV could de- velop circulations to release the instability (e.g., Thorpe and Rotunno 1989), Jones and Thorpe (1992) showed that finite regions of negative $\mathrm{PV}$ in a threedimensional flow were unstable to roll circulations. Jones and Thorpe (1992) did not address the presence of frontogenesis, a limitation addressed by Xu (1992). He showed that multiple banding could be formed by the release of moist symmetric instability by ascending motion above a frontal zone. Specifically, multiplebanded, narrow regions of ascent and descent occurred within the broad moist ascent above the frontal zone (Figs. 5 and 6 in Xu 1992). Such a situation is similar to the present case where dry symmetric instability occurs above a frontal zone and the multiple bands form aloft above the frontal zone within the region of the instability.

The most relevant theory for tropospheric inertial instability in the midlatitudes was developed by Stevens and Ciesielski (1986) using a shallow-water model including horizontal shear. The growth rate for zonally 

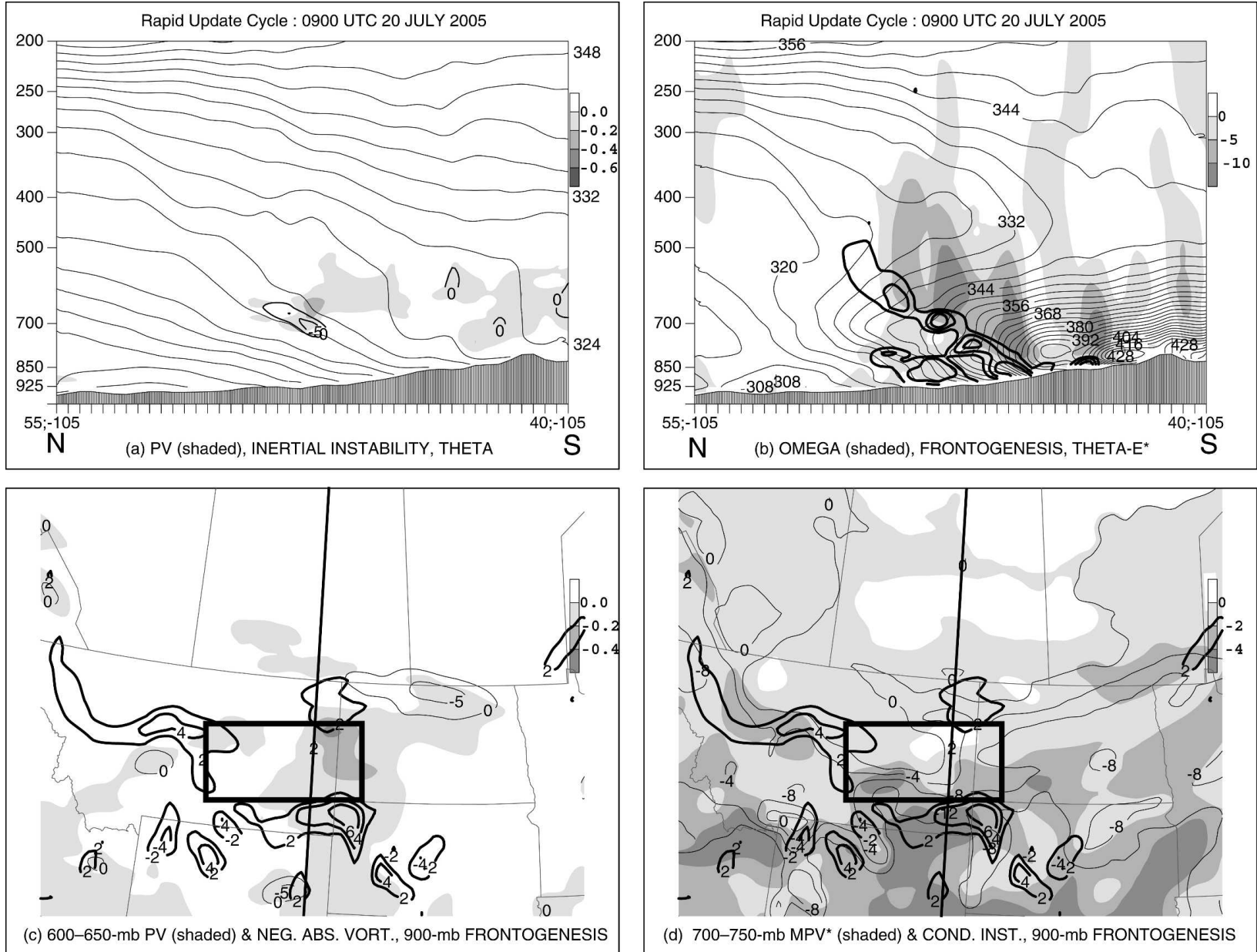

FIG. 11. RUC initialization at 0900 UTC $20 \mathrm{Jul} 2005$. (a) North-south cross section from $\mathrm{N}\left(55^{\circ} \mathrm{N}, 105^{\circ} \mathrm{W}\right)$ to $\mathrm{S}\left(40^{\circ} \mathrm{N}, 105^{\circ} \mathrm{W}\right)$. Negative PV $\left(10^{-6} \mathrm{~K} \mathrm{~m}^{2} \mathrm{~kg}^{-1} \mathrm{~s}^{-1}\right.$, shaded according to scale), negative absolute vorticity (black lines every $-5 \times 10^{-5} \mathrm{~s}^{-1}$ starting at 0 ), and potential temperature (gray lines every $4 \mathrm{~K}$ ). Tick marks on the $x$ axis are every $40 \mathrm{~km}$. (b) Cross section N-S: ascent $\left(\mu \mathrm{b} \mathrm{s}{ }^{-1}\right.$, shaded according to scale), frontogenesis [black lines contoured at 1,2 , and $3 \mathrm{~K}(100 \mathrm{~km})^{-1}(3 \mathrm{~h})^{-1}$ ], and saturated equivalent potential temperature (gray lines every $4 \mathrm{~K}$ ). (c) Negative PV over the layer $600-650 \mathrm{hPa}\left(10^{-6} \mathrm{~K} \mathrm{~m}^{2} \mathrm{~kg}^{-1} \mathrm{~s}^{-1}\right.$, shaded according to scale), negative $600-\mathrm{hPa}$ absolute vorticity (gray lines every $-5 \times 10^{-5} \mathrm{~s}^{-1}$ starting at 0 ), and $900-\mathrm{hPa}$ frontogenesis [black lines every $2 \mathrm{~K}$ (100 $\mathrm{km})^{-1}(3 \mathrm{~h})^{-1}$. (d) Negative moist PV (MPV*) over the layer $700-750 \mathrm{hPa}\left(10^{-6} \mathrm{~K} \mathrm{~m}^{2} \mathrm{~kg}^{-1} \mathrm{~s}^{-1}\right.$, shaded according to scale), the difference in saturated equivalent potential temperature between 700 and $750 \mathrm{hPa}$ (gray lines at $0,-4,-8$, and $-12 \mathrm{~K}$ ), and $900-\mathrm{hPa}$ frontogenesis [black lines every $2 \mathrm{~K}(100 \mathrm{~km})^{-1}(3 \mathrm{~h})^{-1}$ ]. Rectangles in (c) and (d) identify regions where banded clouds and precipitation were observed from satellite and radar imagery. Lines in (c) and (d) represent portions of cross section $\mathrm{N}-\mathrm{S}$ through the plotted domain.

asymmetric inertial instability (i.e., longitudinally finite regions of inertial instability) on a Bickley jet was found to have an upper limit of $(2 / 3) \varepsilon$, where $\varepsilon$ is Ripa's (1983) maximum growth rate for inertial instability in a one-layer model and $\varepsilon=(-\bar{\eta} \tilde{f})^{1 / 2}$ is the product of the zonal-mean absolute vorticity with a modified Coriolis parameter $f+2 U \tan \phi / a$. Stevens and Ciesielski (1986) also found that the length scale of the asymmetric perturbations in the direction of the jet axis was comparable to the width of the unstable region. The phase speed of the perturbations relative to the maximum wind was approximately $-30 \mathrm{~m} \mathrm{~s}^{-1}$ for a range of equivalent depths. Ciesielski et al. (1989) applied these theoretical results to satellite observations of uppertropospheric mesoscale "wavelets" along the anticyclonic side of a strong subtropical jet streak in February 1987 and found good agreement in phase speed, time scale, horizontal length scale, and period.

Turning to our 2005 case, Stevens and Ciesielski's (1986) theory would predict that asymmetric inertial instability in the present case would cause perturbations with a maximum growth rate corresponding to a period of $5.71 \mathrm{~h}$, based on a representative value of $-5 \times 10^{-5} \mathrm{~s}^{-1}$ for the $500-\mathrm{hPa}$ absolute vorticity within 


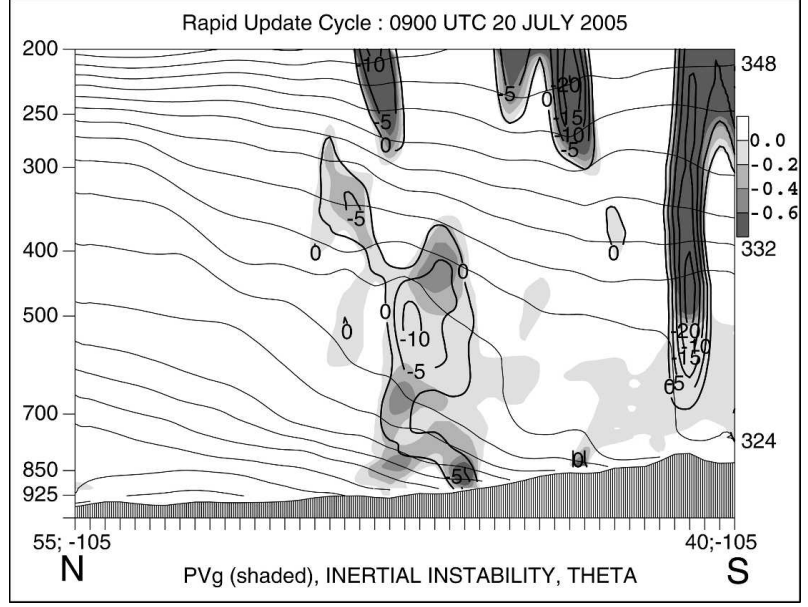

FIG. 12. RUC initialization at 0900 UTC 20 Jul 2005. Northsouth cross section from $\mathrm{N}\left(55^{\circ} \mathrm{N}, 105^{\circ} \mathrm{W}\right)$ to $\mathrm{S}\left(40^{\circ} \mathrm{N}, 105^{\circ} \mathrm{W}\right)$. Negative $\mathrm{PV}_{g}\left(10^{-6} \mathrm{~K} \mathrm{~m}^{2} \mathrm{~kg}^{-1} \mathrm{~s}^{-1}\right.$, shaded according to scale), negative absolute geostrophic vorticity (black lines every $-5 \times$ $10^{-5} \mathrm{~s}^{-1}$ starting at 0 ), and potential temperature (gray lines every $4 \mathrm{~K})$. Tick marks on the $x$ axis are every $40 \mathrm{~km}$.

the region of inertial instability at $500 \mathrm{hPa}$ (e.g., Fig. 10). This region of inertial instability is about $2^{\circ}$ of latitude or about $222 \mathrm{~km}$ in width at $500 \mathrm{hPa}$ at 0900 UTC (Fig. 10a), implying a length scale of the perturbations of roughly $220 \mathrm{~km}$. Given 500-hPa flow in the region of interest of $25 \mathrm{~m} \mathrm{~s}^{-1}$ (Fig. 3), the theory predicts a retrograde motion for any perturbations of -5 $\mathrm{m} \mathrm{s}^{-1}$; in Ciesielski et al. (1989), the wavelets were found to be $5 \mathrm{~m} \mathrm{~s}^{-1}$ slower in the retrograde direction than predicted by theory, and so a similar discrepancy in our case would lead to perturbations stationary with respect to the flow.

Comparing these theoretical expectations to the present case, we find considerable agreement. The time scale of the most prominent banding is about $6 \mathrm{~h}$ from initiation to maximum intensity; the length of the most intense band is $300 \mathrm{~km}$; and individual convective elements remain nearly stationary even though the band develops downstream over time. Each of these results is consistent with asymmetric inertial instability theory.

One concern with applying Stevens and Ciesielski's (1986) theory, however, is the wavelength of the most unstable mode. Stevens and Ciesielski (1990) revisited Ciesielski et al.'s (1989) conclusions in a modeling study and found that the fastest growth rates were at downstream wavelengths greater than $1000 \mathrm{~km}$; the authors concluded that inertial instability was not, after all, the cause of the wavelets in the 1989 paper. However, this modeling study itself did not ultimately prove conclusive (P. Ciesielski 2006, personal communication).

A second issue is that the Stevens and Ciesielski
(1986) theory does not contain frontogenetical forcing, as occurred during the observed case described in this paper. Instead, Stevens and Ciesielski (1986) performed normal mode analysis to find the most rapidly growing infinitesimal perturbations in the absence of larger-scale forcing for ascent. Thus, there may be some concern about applying their theory to this case.

A third concern relates to the release of latent heat in contracting the scale of the ascending plumes. Consistent with the Sawyer-Eliassen equation (e.g., Eliassen 1990), Emanuel (1985) and Thorpe and Emanuel (1985) showed that saturated ascending frontal motion is narrower and more intense than when unsaturated. We expect such a contraction would act with updrafts organized by inertial or symmetric instability, but how to determine the expected narrowing of the bands is unclear.

If several of the characteristics of the convection are consistent with zonally asymmetric inertial instability, then is the banding also related to inertial instability? To our knowledge, there is no theory that explicitly predicts banded features associated with inertial instability in either dry or moist cases. Figure 7b of Stevens and Ciesielski (1986) depicts wavenumber-6 inertial instability in which the wind vectors imply linear eastwest-oriented regions of divergence and convergence; if occurring at much smaller wavelengths, it is plausible that these circulations could, in the presence of moisture, induce multiple, staggered east-west bands of convection.

Although some theory exists for the band spacing in unforced inertial instability, there is, to our knowledge, no extant inertial instability theory or modeling work that would predict the observed $150-\mathrm{km}$ spacing of the convective bands in a moist, frontogenetically forced environment. Simply put, a theory for frontogenetically forced inertial instability in the troposphere has not been developed. Without a detailed modeling study with output more frequent than $1 \mathrm{~h}$, the connection between conditional, symmetric, and inertial instability, the frontogenetical forcing, and the observed banded convection is suggestive, but admittedly speculative.

\section{Similarity to other cases}

The east-west-oriented bands in a region of weak inertial stability is reminiscent of two other cases in the literature. Jascourt et al. (1988) examined the case of 5 June 1986 over eastern Texas and northern Louisiana and hypothesized that upscale development of convective-symmetric instability occurred where a symmetrically stable layer became symmetrically unstable by the release of latent heat by upright convection. The atmo- 

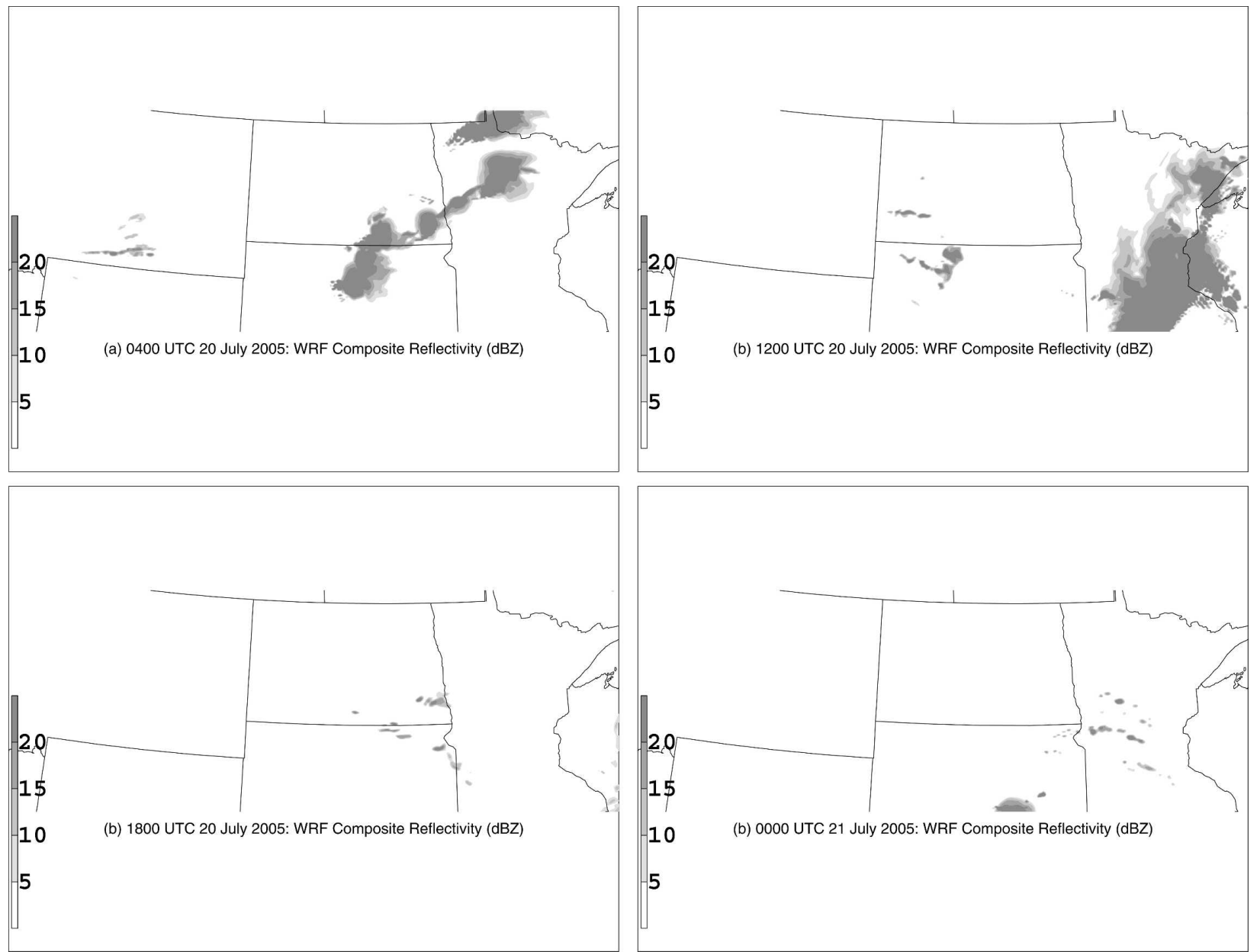

FIG. 13. Composite reflectivity (dBZ) from WRF model initialized at 0000 UTC 20 Jul 2005: (a) 4-h forecast for 0400 UTC, (b) 12-h forecast for 1200 UTC, (c) 18-h forecast for 1800 UTC, and (d) 24-h forecast for 0000 UTC 21 Jul 2005.

spheric response was to produce banded clouds. Knox and Hoggatt (1996) and Knox (2003) presented the case of 14 July 1995 in southern Wisconsin and southern Lake Michigan. They showed that negative absolute vorticity occurred where the bands formed. Highresolution nonhydrostatic modeling of the event (Hoggatt and Knox 1998) revealed a mesoscale checkerboard pattern of vertical motions of alternating sign in the vicinity of the negative absolute vorticity and moisture maxima, similar to O'Sullivan and Hitchman's (1992) numerical results for inertial instability in the middle atmosphere, but on much smaller scales. In all three cases (Jascourt et al. 1988; Knox and Hoggatt 1996; this study), radar imagery from the events showed thin lines composed of broken segments of convective elements.

The environment of the 20 July 2005 banded convection was similar to that of Knox and Hoggatt's (1996) event in that both formed near anticyclones in the middle of the summer in the northern United States. Both events were associated with a very dry atmosphere, and precipitation at the surface was limited, if any. The 20 July 2005 event differed from the Jascourt et al. (1988) event in that the flow was more cyclonic and the atmosphere more moist in the Jascourt et al. (1988) event. The 20 July 2005 event differed from both the other events in that the secondary circulation from lower-tropospheric frontogenesis was present.

Thus, there appears to be some precedent in the literature for this type of event, even if only once a decade. Whether the atmosphere produces these types of events more frequently remains unknown.

\section{Conclusion}

This case shows the extreme sensitivity that some precipitation events can have to environmental parameters. To understand how the bands organized, symmetric and inertial instability were evaluated using both 

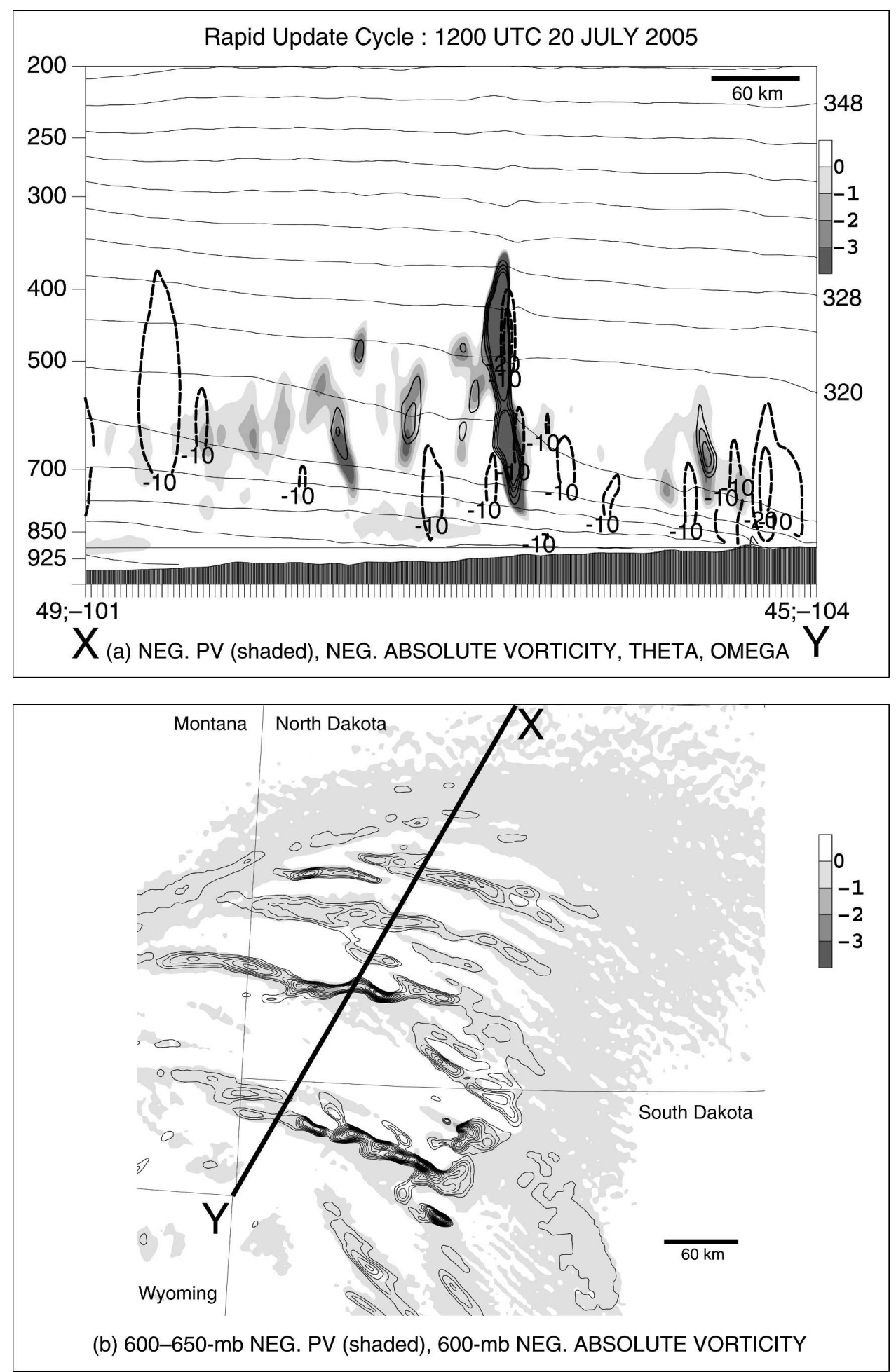

FIG. 14. WRF model 12-h forecast valid at 1200 UTC $20 \mathrm{Jul}$ 2005. (a) Cross section from $\mathrm{X}\left(49^{\circ} \mathrm{N}\right.$, $\left.101^{\circ} \mathrm{W}\right)$ to $\mathrm{Y}\left(45^{\circ} \mathrm{N}, 104^{\circ} \mathrm{W}\right)$. Negative $\mathrm{PV}\left(10^{-6} \mathrm{~K} \mathrm{~m}^{2} \mathrm{~kg}^{-1} \mathrm{~s}^{-1}\right.$, shaded according to scale), negative absolute vorticity (thin solid black lines every $-5 \times 10^{-5} \mathrm{~s}^{-1}$ starting at 0 ), omega (thick dashed black lines contoured at -10 and $-20 \mu \mathrm{b} \mathrm{s}^{-1}$ ), and potential temperature (gray lines every $4 \mathrm{~K}$ ). Tick marks on the $x$ axis are every $4 \mathrm{~km}$. (b) Negative PV over the layer $600-650 \mathrm{hPa}\left(10^{-6} \mathrm{~K} \mathrm{~m}^{2} \mathrm{~kg}^{-1} \mathrm{~s}^{-1}\right.$, shaded according to scale) and negative $600-\mathrm{hPa}$ absolute vorticity (black lines every $-5 \times 10^{-5} \mathrm{~s}^{-1}$ starting at 0 ). Location of cross section $\mathrm{X}-\mathrm{Y}$ in (a) is shown in (b). 
the total and geostrophic wind in their respective criteria. Regardless of how the instability was diagnosed, dry symmetric instability was present in the regions where the bands developed. Large regions of inertial instability were present only when the criterion was computed using the geostrophic wind. Thus, the release of dry symmetric instability, and maybe inertial instability, in a frontogenetical environment appears to be the best hypothesis to explain the organization of the bands. As the bands developed and grew, they had access to conditionally unstable air. Developing bands with greater vertical displacements may have reached their lifting condensating level and level of free convection, saturating and resulting in deep, moist convection. One of the bands produced regions of maximum radar reflectivity factor of about $50 \mathrm{dBZ}$ and measurable precipitation at the surface, although no severe weather was reported.

This case shows the complexities of the real atmosphere when multiple instabilities are simultaneously present. Furthermore, this case indicates the difficulty in applying idealized modeling experiments of the release of dry instabilities to some situations in the real atmosphere because of the complications of finite regions of instability, frontogenetical forcing, and moisture. Numerical simulation of observed cases may have to be employed with sensitivity studies to better understand such events in the future. Clearly, much remains to be learned about the interactions between conditional, symmetric, and inertial instabilities in a region being forced by frontogenesis.

Acknowledgments. We have benefited considerably from discussions with and comments from Peter Banacos, Paul Ciesielski, Charles Doswell, David Dowell, Suzanne Gray, Daniel Keyser, Stephen Jascourt, John Nielsen-Gammon, David Novak, David Stensrud, and Qin Xu. Russ Schumacher showed us that the WRF produced the bands, and Michael Baldwin obtained the WRF output. Much of the data in this paper came courtesy of the NOAA/NWS/NCEP/Storm Prediction Center. Funding for Schultz was provided by the NOAA/ Office of Oceanic and Atmospheric Research under NOAA-University of Oklahoma Cooperative Agreement NA17RJ1227, U.S. Department of Commerce.

\section{REFERENCES}

Benjamin, S. G., and Coauthors, 2004: An hourly assimilationforecast cycle: The RUC. Mon. Wea. Rev., 132, 495-518.

Ciesielski, P. E., D. E. Stevens, R. H. Johnson, and K. R. Dean, 1989: Observational evidence for asymmetric inertial instability. J. Atmos. Sci., 46, 817-831.

Clark, J. H. E., R. P. James, and R. H. Grumm, 2002: A reexami- nation of the mechanisms responsible for banded precipitation. Mon. Wea. Rev., 130, 3074-3086.

Doswell, C. A., III, 1977: Obtaining meteorologically significant surface divergence fields through the filtering property of objective analysis. Mon. Wea. Rev., 105, 885-892.

- , and E. N. Rasmussen, 1994: The effect of neglecting the virtual temperature correction on CAPE calculations. Wea. Forecasting, 9, 625-629.

Eliassen, A., 1990: Transverse circulations in frontal zones. Extratropical Cyclones: The Erik Palmén Memorial Volume, C. W. Newton and E. O. Holopainen, Eds., Amer. Meteor. Soc., 155-165.

Emanuel, K. A., 1985: Frontal circulations in the presence of small moist symmetric stability. J. Atmos. Sci., 42, 1062-1071.

Gray, S. L., and A. J. Thorpe, 2001: Parcel theory in three dimensions and the calculation of SCAPE. Mon. Wea. Rev., 129, $1656-1672$.

Hitchman, M. H., C. B. Leovy, J. C. Gille, and P. L. Bailey, 1987: Quasi-stationary, zonally asymmetric circulations in the equatorial middle atmosphere. J. Atmos. Sci., 44, 2219-2236.

Hoggatt, B. D., and J. A. Knox, 1998: Non-hydrostatic simulation of unforecast convection in an intense mid-latitude anticyclone. Preprints, 16th Conf. on Weather Analysis and Prediction/12th Conf. on Numerical Weather Prediction, Phoenix, AZ, Amer. Meteor. Soc., 59-62.

Holt, M. W., and A. J. Thorpe, 1991: Localized forcing of slantwise motion at fronts. Quart. J. Roy. Meteor. Soc., 117, $943-$ 963.

Jascourt, S. D., S. S. Lindstrom, C. J. Seman, and D. D. Houghton, 1988: An observation of banded convective development in the presence of weak symmetric stability. Mon. Wea. Rev., 116, 175-191.

Johns, R. H., and C. A. Doswell III, 1992: Severe local storms forecasting. Wea. Forecasting, 7, 588-612.

Jones, S. C., and A. J. Thorpe, 1992: The three-dimensional nature of "symmetric" instability. Quart. J. Roy. Meteor. Soc., 118, 227-258.

Jurewicz, M. L., Sr., and M. S. Evans, 2004: A comparison of two banded, heavy snowstorms with very different synoptic settings. Wea. Forecasting, 19, 1011-1028.

Knox, J. A., 2003: Inertial instability. Encyclopedia of the Atmospheric Sciences, J. Holton, J. Pyle, and J. Curry, Eds., Academic Press, 1004-1013.

_ , and B. D. Hoggatt, 1996: Mesoscale dynamics of mid-level convection in an intense mid-latitude anticyclone. Preprints, Seventh Conf. on Mesoscale Processes, Reading, United Kingdom, Amer. Meteor. Soc., 453-455.

McNulty, R. P., 1978: On upper tropospheric kinematics and severe weather occurrence. Mon. Wea. Rev., 106, 662-672.

NCDC, 2005: Storm Data. Vol. 47, No. 7, 398 pp.

Nielsen-Gammon, J. W., and D. A. Gold, 2007: Dynamical diagnosis: A comparison of quasigeostrophy and Ertel PV. The Fred Sanders Symposium Volume, Meteor. Monogr., Amer. Meteor. Soc., in press.

Novak, D. R., L. F. Bosart, D. Keyser, and J. S. Waldstreicher, 2004: An observational study of cold season-banded precipitation in northeast U.S. cyclones. Wea. Forecasting, 19, $993-$ 1010.

_ J. S. Waldstreicher, D. Keyser, and L. F. Bosart, 2006: A forecast strategy for anticipating cold season mesoscale band formation within eastern U.S. cyclones. Wea. Forecasting, 21, 3-23.

O'Sullivan, D. J., and M. H. Hitchman, 1992: Inertial instability 
and Rossby wave breaking in a numerical model. J. Atmos. Sci., 49, 991-1002.

Ripa, P., 1983: General stability conditions for zonal flows in a one-layer model on the beta-plane or the sphere. J. Fluid Mech., 126, 463-489.

Roebber, P. J., D. M. Schultz, B. A. Colle, and D. J. Stensrud, 2004: Toward improved prediction: High-resolution and ensemble modeling systems in operations. Wea. Forecasting, 19, 936-949.

Schultz, D. M., and P. N. Schumacher, 1999: The use and misuse of conditional symmetric instability. Mon. Wea. Rev., 127, 2709-2732; Corrigendum, 128, 1573.

Skamarock, W. C., J. B. Klemp, J. Dudhia, D. O. Gill, D. M. Barker, W. Wang, and J. G. Powers, 2005: A description of the Advanced Research WRF Version 2. NCAR Tech. Note NCAR/TN-468+STR, 100 pp. [Available online at http:// www.wrf-model.org/wrfadmin/docs/arw_v2.pdf.]
Stevens, D. E., and P. E. Ciesielski, 1986: Inertial instability of horizontally sheared flow away from the equator. J. Atmos. Sci., 43, 2845-2856.

— and —, 1990: Dynamic modeling of an observed mesoscale jet instability. Preprints, Fourth Conf. on Mesoscale Processes, Boulder, CO, Amer. Meteor. Soc., 172-173.

Thorpe, A. J., and K. A. Emanuel, 1985: Frontogenesis in the presence of small stability to slantwise convection. J. Atmos. Sci., 42, 1809-1824.

_ and R. Rotunno, 1989: Nonlinear aspects of symmetric instability. J. Atmos. Sci., 46, 1285-1299.

Uccellini, L. W., and S. E. Koch, 1987: The synoptic setting and possible energy sources for mesoscale wave disturbances. Mon. Wea. Rev., 115, 721-729.

$\mathrm{Xu}, \mathrm{Q} ., 1992$ : Formation and evolution of frontal rainbands and geostrophic PV anomalies. J. Atmos. Sci., 49, 629-648. 